\title{
Free Personal Care for Older People in Scotland: Issues and Implications
}

\author{
Alison Bowes* and David Bell** \\ * Department of Applied Social Science \\ **Department of Economics, University of Stirling \\ E-mail: a.m.bowes@stir.ac.uk
}

Drawing on recent quantitative and qualitative research, we consider lessons of the Scottish policy of free personal care for older people. The policy is embedded in political debates about devolution and interacts with various changing policies on care and support for older people. Evaluation is complicated by these interactions and by gaps in relevant data, especially concerning costs. Operationally, policy implementation has presented varying difficulties for local authorities. For clients and informal carers it remains popular, but is part of a service-led model of provision which does not reflect their own views of their care and support needs.

\section{Background - a natural experiment?}

In 2002, charges for personal care for older people living in their own homes or in care homes in Scotland were abolished, and local authorities prohibited from charging for such services. In this measure Scotland differed from the rest of the UK, where charging continued to be permitted. Scotland alone of the jurisdictions of the United Kingdom thus implemented the recommendation of the Royal Commission on Long Term Care for Older People (1999) that personal care should be free for all who needed it.

Free personal care was represented as a 'flagship' policy by the new Scottish Parliament (formed at devolution in 1999) and thus invested with ideological significance. The Westminster government, responsible for social care in England, set itself firmly against removing charges for personal care (though nursing care was free), claiming, along with the minority report of the Royal Commission, that costs would be unsustainable as numbers of older people needing care increased. UK-wide, the continuing debate has focused on costs, moving away from key considerations of social justice which the Royal Commission had highlighted.

Throughout the UK, the challenges for government in providing for the care needs of an ageing population are broadly similar. In Scotland, the proportion of older people is approximately the same relative to the whole UK, and projected rates of increase in these proportions are similar. The proportions of older people needing care and support are also consistent across the UK. Life expectancy and healthy life expectancy are somewhat lower in Scotland, and older people appear a little less affluent than in other parts of the UK. These differences are due to particularly high levels of deprivation in one area, West Central Scotland (see Bell and Bowes 2006 for detailed analysis), and thus the inter-country differences are less significant. 
The case of free personal care in Scotland provides an opportunity to explore issues in implementing a 'new' charging regime, and in evaluating such a development. In the paper, we explore some emerging lessons, drawing on research completed for the Joseph Rowntree Foundation (Bell and Bowes, 2006) and the Scottish Executive (Bell, Bowes, Dawson and Roberts, 2006). In particular, our discussion places questions of costs in their broader context, focusing on the interactions of policies, local circumstances and choices made by older people and informal carers themselves.

Our concern is not to report research findings in detail ${ }^{1}$, but to explore a range of issues raised by our evaluation of the policy, including the significance of its political and policy context. In the context of myth-making and confusion, we consider the actual experience of the policy for those charged with implementing it - local authorities - and those on its receiving end - older people and informal carers. In conclusion, we highlight some of the wider lessons of the policy and its evaluation.

\section{The policy context}

Free personal care was introduced at a time of rapidly evolving policy for older people in the UK and Scotland, and it is important to recognise that this complicates attempts to explore the policy's impact. The legislation (the Community Care and Health (Scotland) Act 2002) defines personal care as including help with personal hygiene, continence management, assistance with eating and mobility, counselling and support services, assistance with medication and simple treatments and personal assistance such as help getting up and going to bed. It requires that local authorities do not charge for personal care clients are assessed as needing. Charges for non-personal care, housing support services and 'hotel' costs in care homes may still be levied, following means testing. The evaluation strategy (Scottish Executive, 2005a: 2) identifies 'aims' including the promotion of care at home, equity in service provision, consistent range and quality of service provision and the removal of discrimination. These aims reflect the broader thrust of recent policy developments, which we now highlight.

In Scotland, a significant shift in the balance of care towards increased provision of care at home was apparent before the introduction of free personal care, and has continued since (Bell et al., 2006a). Since the late 1990s, the Scottish Office (until 1999) and the Scottish Executive (after devolution) have shared with the UK government its commitment to supporting older people to stay in their own homes, receiving any care they may need without moving to hospital or care home settings unless this is absolutely necessary. Whilst recent changes have proceeded alongside one another, it is difficult to establish causation.

Joint working between professionals has been seen as supporting flexibility in services and therefore better choice for users, as well as promoting equity through standardisation (Alaszewski et al., 2004). Single shared assessment, whereby older people with care needs receive one, comprehensive assessment, for use by all the professionals involved in their case has been implemented ${ }^{2}$ rather slowly, but, in theory, should have contributed to a general improvement in services for older people, not least by avoiding perceived repeated assessments by different professional groups and by supporting a standard, systematic approach to assessment.

Multiple policies have addressed boundary issues, and their individual effects are difficult to distinguish, as other research has demonstrated in several contexts (e.g. 
Dowling et al., 2004; Leichsenring and Alaszewski, 2004). Joint working between agencies in Scotland (known as 'integrated care' - Petch, 2003) involved health and social care services in particular, and has been argued to avoid 'artificial' boundaries between health and social care (cf. Lewis, 2001; Abbott and Lewis, 2002). The Royal Commission (1999) noted that the boundaries of health care and social care were particularly problematic in cases of people with chronic conditions, including dementia, whose social and personal care needs resulted from a medical condition. Thus, for the majority report, the provision of free personal care was a logical solution to these problems.

Free personal care was presented as an improvement in service provision, as were other measures. The Scottish Commission for the Regulation of Care now monitors and inspects care services, including services for older people, many of which offer personal care, against National Care Standards (Scottish Executive, 2004). The 'Care Commission', as it is commonly known, is also required to provide information and advice about services and to deal with complaints. The Commission thus acts as a 'watchdog' for services, and sets standards with which providers must comply. In theory, it should help raise standards of services as well as raising people's expectations, and this is one of its acknowledged tasks (Care Commission, 2004). Higher standards also have the potential to increase costs, including costs of personal care, and this was not necessarily anticipated.

The extreme complexity of the various sources of financial support for older people and the unpopularity of means-testing have been highlighted by Croucher and Rhodes (2006) and the Joseph Rowntree Foundation (2006). As we will later discuss, they are also out of tune with older people's own perceptions and preferences and they contribute towards the difficulties of identifying and understanding the costs of provision. In addition to a state and possibly a private pension, older people may receive a range of benefits. These may include:

- Attendance Allowance, a non-means tested benefit from the UK Department for Work and Pensions, which is intended to give support with personal care needs due to disability. In Scotland, older people in residential care do not receive this benefit, as the local authority, through the policy of free personal care, is contributing to the costs of their care. However, those receiving care at home may continue to receive it.

- 'Supporting People' funding, which is means-tested, covers a specified list of types of housing based support, such as safety and security, budgeting, aids and adaptations, some social support, cleaning, and support from contacts with professionals.

- Direct Payments, for which older people with care and support needs have been eligible since April 2005. These provide a financial allowance to buy one's own care, though take-up has been low (Riddell et al., 2005) due to include lack of information and support for clients, and some negativity towards the principle of such payments on the part of professionals (Glasby, 2002; Clark and Spafford, 2002).

Research has demonstrated support for the principle of free personal care in Scotland (Dewar et al., 2003a, 2003b; Curtice and Petch, 2002). Scottish policy on service improvement has user consultation as a central element. Andrews et al. (2004, citing Crawford et al., 2002) argue that user involvement can have a significantly positive impact on both design and delivery of services. In the case of services for older people the client population also involves informal carers, though there is a recognised need in recent research to ensure that older people speak for themselves, and that the potential 
for differences of view between informal carers and those for whom they care must be recognised (e.g. Stalker, 2003). Thus, an essential element of the impact of the free personal care policy has to be its impact for individuals. Public debate at implementation produced a number of doom-laden scenarios regarding the reaction and behaviour of older people in response to the provision of free personal care. These included hugely increased demand, a withdrawal of informal carers from their contributions to supporting older people, and migration from England to Scotland on a large scale, all leading to insatiable demand and escalating costs. In the event, none of these scenarios has occurred, adding further support to the need to give particular attention to the views and experiences of older people and informal carers about free personal care.

\section{Research methods ${ }^{3}$}

The research on which this discussion is based involved secondary analysis of a wide range of large datasets including UK census data, Scottish Executive datasets on aspects of health and social care, Audit Scotland performance indicators for housing and social work, the British Household Panel Survey, Department for Work and Pensions data on benefits, Department of Health data on nursing and home care and Government Actuary's Department population forecasts. We carried out simulations of a number of future scenarios relating to policy sustainability.

To explore the implementation process qualitatively, we conducted 20 interviews and one group discussion with people involved in implementing the policy at strategic, tactical and operational levels. To look at the experiences and views of older people, we conducted 15 focus groups involving 88 people, 37 of whom were receiving social care services and 51 of whom belonged to organisations of older people and/or informal carers. All except one of these were 'natural' groups, that is, they consisted of people who already knew one another.

A full account of research findings has been given elsewhere (Bell and Bowes, 2006). In this discussion, we focus on some of the key emerging issues and their wider implications.

\section{Some key issues}

We now consider aspects of the impact of free personal care. These are: first, its political basis and the ensuing debate; second, its interactions with other policies and demographic changes; third, its impact on the costs to the public purse of caring for older people; fourth, issues of policy implementation at the operational level; and finally, the effect of the policy for the intended beneficiaries, older people and informal carers.

\section{Political impact}

Free personal care was and continues to be seen as a 'flagship' policy of the new Scottish Parliament and involved significant political investment by the administration. Dickinson and Glasby (2006) highlight the intense debate which took place at implementation, describing the policy as inextricably tied into the survival of the coalition government. They also note that the policy could be seen, both by supporters and detractors of devolution, as epitomising the potential of devolved government. It represented a major 


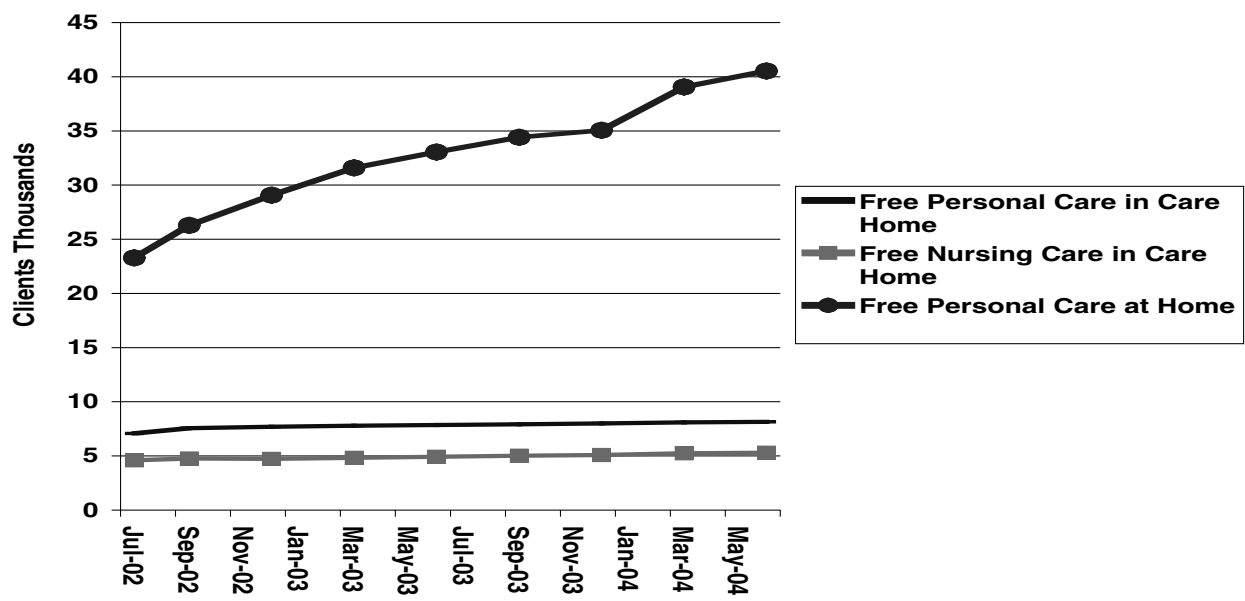

Figure 1. Clients receiving free personal care July 2002-May 2004.

Source: Scottish Executive, 2005b.

policy departure by the Scottish Parliament from the Westminster regime and had significant symbolic value for that reason, being described as a 'defining moment' for devolution (Martin, 2006).

Continuing press and political debate about the policy have illustrated this symbolic value. Of 189 newspaper articles about free personal care published during June 2006, nearly 40 per cent used the term 'flagship' - this terminology has become routinised in media coverage. The Scottish Parliament Health Committee Inquiry into care legislation selected free personal care as one of its key topics, and the report (Scottish Parliament Health Committee, 2006) endorses Parliament's continuing commitment to it. However, the Inquiry identified a number of difficulties with funding. In the report, these are presented as technical difficulties, potentially requiring increased funding or redistribution of funding among local authorities (who deliver the policy). However, the subsequent press debate focused for example on waiting lists, differences between councils in their management of funds, and revisited questions about the overall sustainability of the policy. On publication of our second report (Bell et al., 2006a), press coverage was again critical of the policy, this time highlighting not the actual (or purported) high costs, but the lack of clear data which would allow its impact to be properly considered.

\section{Free personal care in context}

It is difficult to distinguish the effects of free personal care from wider changes in the system of care and support for older people and from demographic pressures. For example, Figure 1 shows levels of free personal care receipt for the first three years following the introduction of the policy. There is a marked increase in receipt of free personal care at home, and a small increase for care home residents. One reading of this data is that the policy has increased demand for services, especially at home. However, there are several reasons why this reading is questionable. First, the allocations of free personal care monies to care homes were based on total numbers of residents who were assumed to be in need 
of personal care - they were not reassessed. Second, the funding for people in care homes was fixed at a standard rate ${ }^{4}$. Both these factors, combined with the policy imperative to keep people in their own homes would tend to moderate any increases in recipients of free personal care in care homes. Third, clients living in their own homes were reassessed before being given free personal care. This was a lengthy process, with time-lags as people came gradually into the system. Fourth, the number of people requiring care at home was rising independently of the payment regime. Thus in this example, the trend is 'explained' by implementation issues, wider policy changes and demographics. Other examples are similarly complicated, for example, the question of whether Care Standards have increased expectations of and/or demand for services cannot easily be answered.

\section{Costs}

Free personal care did not in itself increase the overall costs of care, but shifted responsibility for some of these into the public purse. Debate has concerned the extent of the new call on the public purse, and subsequent changes in supply of services.

The Care Development Group, charged by the Executive with the task of bringing the policy to implementation, used information available at the time to calculate the future costs of the free personal care policy. However, much of this information was subsequently found to be inaccurate. In particular, the population estimates were revised upwards. The Audit Committee of the Scottish Parliament (2005c) was subsequently highly critical of the Executive for a failure to understand the costs of the policy, to monitor or evaluate its delivery:

The Committee considers that $\mathrm{SEHD}^{5}$ has failed to monitor the actual cost of the free personal care policy following implementation. (Scottish Parliament Audit Committee, 2005c: 4)

The Scottish Executive (2005a) subsequently published its evaluation strategy for free personal care which, for the first time, highlighted the aims of the policy.

The Health Committee Inquiry report (2006) was unable to identify the actual costs of free personal care, and renewed calls to do so, to support potential changes or redistributions of funding among local authorities.

Our research (Bell and Bowes, 2006) explored the issue of costs in some depth, including the future costs of care to the public purse. In identifying the actual costs involved, we found that costs of care of older people in Scotland and in England were much more similar than much of the public debate had acknowledged. Within Scotland, however, we found marked variation in expenditure on care of older people and differences in the balance of care among local authorities. These differences could be explained by a combination of local demographics, local models of care and charging policies, and emphasise the degree of autonomy of local authorities in their spending. The resources for free personal care were not ring-fenced, and councils have a statutory responsibility to provide services, which is not linked to clearly identifiable elements of their financial provision from the Executive, even though the Executive allocates some of this funding on the basis of calculations of the costs of free personal care. Overall, it emerged that there was limited understanding of the costs of care and support for older people, and significant gaps in data which would allow these to be calculated accurately 
(Bell et al., 2006a). A holistic approach was particularly difficult because of the separation of health and social care budgets.

We also explored the sustainability of the policy by examining its future costs in relation to a number of potential developments. First, assuming 2 per cent economic growth and no increase in the real cost of care per individual, total costs rose to a peak of 0.28 per cent of GDP in 2038, then fell back again. If costs rose at a real rate of 2 per cent, the peak was at 0.63 per cent of GDP in 2058. Second, the loss of an increasing number of potential self-funders, due to increasing rates of home ownership (asset wealth) in Scotland, increased the costs to the public purse by around 0.06 per cent of GDP. Third, a shift towards more care at home would very significantly moderate costs. Fourth, if economic growth only averages 1 per cent while the real costs of care increase at 2 per cent, the costs of free personal care rise to 1 per cent of GDP by 2053. Thus, the future costs of the policy measured as a share of economic activity remain uncertain, not least because of the role of economic growth.

Nevertheless, our research identified that a shift in the balance of care towards care at home could moderate costs. Furthermore, political will to devote a larger share of public resources to the support of older people needing care could reduce the impact of costs at local level. Thus, the costs of the policy are not simply a matter of demography, but can be influenced by political will.

\section{Operational impact}

Service providers and policy implementers interviewed (Bell and Bowes, 2006) saw free personal care against the background of wider debates about care and support for older people. They expressed general support for improving quality and particularly for increased emphasis on care at home, and choices for older people. They had found difficulties in responding to what they perceived as many, rather piecemeal policy changes, and felt that a more strategic approach to reform would have been helpful.

There was evidence of some confusion, especially at operational level, about the free personal care policy and its interactions with other policies, exemplified by meal preparation. Guidance issued in 2002 did not include this as part of free personal care. However, this was found to be contrary to legislation, and in 2004 the Executive permitted the inclusion of meal preparation as part of personal care. Despite this attempt to clarify matters, the issue was repeatedly raised by our interviewees, and continues to be discussed. For example, in June 2006, the issue of paying for meal preparation was described as prompting a 'stand-off between councils, clients and ministers' (Fraser, 2006: 9) as a number of cases went to court.

Our respondents identified various perceived consequences of the policy. All these can be related back to the wider policy changes we discussed, and particularly to the generally increased pressure on the system from demographics and improving standards. Free personal care appeared thus as one element in a more general picture of concern. First, respondents felt that there had been some substitution out of informal care, but no-one was able to quantify this - our statistical analysis however suggested that in fact informal caring had not reduced, despite the expectation of the Executive that it would (and the inclusion of $£ 8$ million in the funding to cover this eventuality). Second, respondents highlighted increases in care home charges since the introduction of the policy - some felt that this was an example of profiteering on the part of the private care 
home sector, maximising its income from the extra money now in the system. However, others noted that these price rises would almost certainly have occurred without free personal care. Third, respondents noted an increase in complaints about care at home, acknowledging that these were linked with more generally raised expectations of care quality as well as the increasing volume of care at home being delivered. Fourth, they raised issues connected with the workforce, notably the need for better training and support for workers, as well as the increasing shortage of people available to do care work alongside increased demand.

In local authorities, the impact of the policy was described as varied according to local circumstances. Factors influencing variation included:

- previous practices, whereby some authorities had already offered free personal care following a local decision to do so;

- local demographics, especially the existing proportion of self-funders who became a new charge on the local authority budgets;

- local conditions, such as the particular costs of delivering services at home to a dispersed, rural population;

- and difficulties with the allocation of funds to authorities.

All these points tended to support the strategy of permitting local authority discretion over the expenditure of the extra funds they received for free personal care. However, they also indicate that for some local authorities, these extra funds were a mixed blessing. In authorities with large numbers of self-funders receiving care at home, the increased expenditure due to personal care becoming free was more problematic, compared with authorities where there had been few self-funders. Some authorities suggested that the costs of free personal care went beyond the extra allocation of funds.

In the voluntary and private sectors, free personal care had had some perhaps unanticipated consequences. For the voluntary sector, raised expectations engendered in association with the policy (notably the widespread misconception that all care would henceforth be free) had produced an increased volume of enquiries, with which voluntary sector groups felt ill-equipped to deal. For the private sector, it was noted that there was a tendency to 'demonise' private sector providers for raising prices, when in fact the economics of providing care homes had already produced severe pressure for all care homes, which local authorities and the voluntary sector could not fund alone.

\section{Clients' perspectives}

The effects of the policy for the intended beneficiaries, older people and informal carers, have to be understood in a context in which community care and choice had been promoted for some years. Free personal care was widely advertised and it was clear that several of our focus group participants, like other members of the public (Dickinson and Glasby, 2006) had believed that all care was therefore going to be free.

Overwhelmingly the focus group discussions demonstrated that older people themselves (and their informal carers) have a holistic view of needs for care and support, and do not naturally operate with the fine distinctions and classifications of tasks that the care system uses. Distinctions between personal care, non-personal care, housing support, 'hotel' costs and so on meant little to people seeking care. Uppermost in people's concerns was the quality of services, felt in many cases to fall short. 
It was also clear that older people are not mere passive recipients of services, but actively negotiate and build their own 'packages' of care and support, drawing on a range of resources including private arrangements (with house cleaner or gardeners for example) and neighbour and family relationships. ${ }^{6}$ Formal care services may be part of these packages. Many of our participants had a wealth of knowledge and experience of finding care and support from various places, sometimes including formal services. However, it was notable that significant confusion and lack of clear knowledge about free personal care remained. People were not clear about what was included in 'free personal care' or how to get access to it. Despite the confusion, we found that focus group participants were supportive of the policy, expressing the view that free care in older age was a just reward for a lifetime's work and contribution.

Perspectives on the role of informal carers were similarly holistic, and there were frequent references to carers who worked hard and alone, without support. Indeed, the need for support for informal carers was one of people's main concerns and they saw the availability of free personal care as supporting informal carers, not as replacing their efforts. Significantly, commitment to informal care was emphasised, and people clearly intended to continue providing it. The notion that people might calculate their caring in relation to what the state might offer appeared quite alien to the thinking reflected among our participants. There were no indications therefore in our qualitative work with older people and informal carers that free personal care would result in a reduction of informal care. This conclusion is supported by analysis of available statistics (Bell et al., 2006b).

\section{Conclusions}

The free personal care policy, as we have shown, is complex. It is embedded in political debates about devolution and Scottish and UK governance, and symbolises in many respects the ability of the Scottish Parliament to exercise power. It is not therefore surprising that much myth and counter-myth surrounds it and that continuing debate is ill-informed.

Furthermore, the impact of the policy is difficult to evaluate, not least because of gaps in the data available, as well as because of conceptual issues in separating out the impact of free personal care from other policies. It is possible to identify trends and changes in the provision of care and support for older people, but much more difficult to attribute these to the effects of free personal care - or to other particular elements of policies for older people.

In terms of costing the policy, there have been difficulties in the absence of appropriate data - in particular, the pre-policy costs are not known because personal care was not at that stage distinguished. In many ways, this emphasises the inherent artificiality of the boundary between personal care and other forms of care. There are particular data weaknesses in Scotland, which is one of few European jurisdictions without a longitudinal survey of older people, who remain excluded from some surveys or included in such small numbers as to make meaningful statistical analysis impossible.

The case of Scotland illustrates the importance of intra-country variations, over and above inter-country ones. We found that the overall picture in England and Scotland varied little in terms of demographics, care needs and the costs of care. However, significant differences emerged among different parts of Scotland in all these respects.

Despite the rhetoric of increasing choice for clients, a service-led model of provision continues to prevail in Scotland, as in the rest of the UK. Older people and informal 
carers differ fundamentally in their perspective on their needs for care and support from the perspective of care providers. Care providers continue to divide care needs into categories, whilst older people and informal carers see these holistically, and find difficulties in working with the distinctions operated by the formal care system.

\section{Acknowledgements}

We are grateful to the Joseph Rowntree Foundation and the Scottish Executive for research funding.

\section{Notes}

1 This has been done elsewhere (Bell and Bowes 2006, Bell et al. 2006).

2 Using the tool 'Single Shared Assessment Indicator of Relative Need' (SSA-loRN).

3 A full account of methods is included in the report (Bell and Bowes 2006) and we do not repeat it here.

4 These rates are $£ 145$ per week for personal care and $£ 65$ per week for nursing care. They have remained unchanged since implementation until the time of writing (November 2006). These standard rates do not apply for care at home.

5 Scottish Executive Health Department.

6 Independent of the low uptake of Direct Payments previously noted.

\section{References}

Abbott, S. and Lewis, H. (2002), 'Partnership working and eligibility criteria: what can we learn from the implementation of guidance on continuing health care?', Social Policy and Administration, 36(5): 532-543.

Alaszewski, A., Billings, J. and Coxon, K. (2004), 'Integrating health and social care for older persons: theoretical and conceptual issues', in K. Leichsenring and A.M. Alaszewski (eds), Providing Integrated Health and Social Care for Older Persons: A European Overview of Issues at Stake, Aldershot: Ashgate, pp. 53-94.

Andrews, J.A., Manthorpe, J. and Watson, R. (2004), 'Involving older people in intermediate care', Journal of Advanced Nursing, 46(3): 303-310.

Bell, D. and Bowes, A. (2006), Financial Care Models in Scotland and the UK, York: Joseph Rowntree Foundation.

Bell, D., Bowes, A., Dawson, A. and Roberts (2006a), Establishing the Evidence Base for an Evaluation of Free Personal Care in Scotland, Edinburgh: Scottish Executive, http://www.scotland.gov.uk/ Publications/2006/06/16110723/0, accessed on 5 January 2007.

Bell, D., Heitmueller, A. and Bowes, A. (2006b), 'Did the introduction of free personal care in Scotland result in a reduction of informal care', paper presented at IZA Workshop, the well-being of the elderly: income, consumption, and health - cross-country perspectives, Bonn, Germany, 22-23 May 2006.

Care Commission (2004), A Review of the quality of care homes in Scotland, Dundee; Care Commission.

Clark, H. and Spafford, J. (2002), 'Adapting to the culture of user control?', Social Work Education, 21(2): 247-257.

Crawford, M., Rutter, D., Manley, C., Weaver, T., Bhui, K., Fulop, N. and Tyler, P. (2002), 'Systematic review of involving patients in the planning and development of healthcare', British Medical Journal, 325: 1263-1265.

Croucher, K. and Rhodes, P. (2006), Testing Consumer Views on Paying for Long Term Care http://www.jrf.org.uk/bookshop/ebooks/9781859354957.pdf, 5 January 2007. 
Curtice, L. and Petch, A. (2002), How Does the Community Care? Public Attitudes to Community Care in Scotland, Scottish Executive Social Research.

Dewar, B., O'May, F. and Walker, E. (2003a), 'Care provision in Scotland: background, policy context and research', Nursing Older People, 14(10): 14-16.

Dewar, B., O'May, F. and Walker, E. (2003b), 'Care provision in Scotland: experiences of services and priorities for improvement', Nursing Older People, 15(1): 14-16.

Dickinson, H. and Glasby, J. (2006), Free Personal Care in Scotland, London: King's Fund http://www.kingsfund.org.uk/resources/publications/appendices_to.html, 5 January 2007.

Dowling, B., Powell, M. and Glendinning, C. (2004), 'Conceptualising successful partnerships', Health and Social Care in the Community, 12: 309-317.

Fraser, D. (2006), 'Free care row reaches court with test case over $£ 1700$ bill', The Herald (Glasgow), 8 June, p. 9.

Glasby, J. (2002), 'Independence at a price', Community Care, 29 August 2002, pp. 30-31.

Joseph Rowntree Foundation (2006), Paying for Long-term Care, York: Joseph Rowntree Foundation, http://www.jrf.org.uk/KNOWLEDGE/FINDINGS/foundations/pdf/0186.pdf, 5 January 2007.

Leichsenring, K. and Alaszewski, A. (2004), Providing Integrated Health and Social Care for Older Persons: A European Overview of Issues at Stake, Aldershot: Ashgate.

Lewis, J. (2001), 'Older people and the health - social care boundary in the UK: half a century of hidden policy conflict', Social Policy and Administration, 35(4): 343-359.

Martin, T. (2006), 'Executive's pledges of free elderly care are proving far too ambitious', Sunday Express, Scottish Edition, 18 June, p. 8.

Petch, A. (2003), 'Intermediate care or integrated care: the Scottish perspective on support provision for older people', Journal of Integrated Care, 11(6): 7-14.

Riddell, S., Pearson, C., Jolly, D., Barnes, C., Priestley, M. and Mercer, G. (2005), 'The development of direct payments in the UK: implications for social justice', Social Policy and Society, 4(1): 75-85.

Royal Commission on Long Term Care (1999), With Respect to Old Age: Long Term Care - Rights and Responsibilities, Cm 4192-I: 1999, London: The Stationery Office.

Scottish Executive (2004), National Care Standards: Care at Home, http://www.scotland.gov.uk/ Topics/Health/care/17652/9827, 5 (January 2007).

Scottish Executive (2005a) Evaluation Strategy for the Policy of Free Personal Care, 13 July, http:// www.scotland.gov.uk/Resource/Doc/55971/0015596.pdf, accessed on 5 January 2007.

Scottish Executive (2005b), Community Care Statistics, http://www.scotland.gov.uk/Publications/2005/11/ 28160037/00376, accessed on 5 January 2007.

Scottish Parliament Audit Committee (2005c), Second Report, session 2 Scottish Executive Health Department Response, http://www.scottish.parliament.uk/business/committees/audit/reports-05/aur05-02-response.pdf, accessed on 5 January 2007.

Scottish Parliament Health Committee (2006), Care Inquiry Final Report, http://www.scottish. parliament.uk/business/committees/health/reports-06/her06-10-vol01-01.htm\#FPCE, accessed on 5 January 2007.

Stalker, K. (ed.) (2003), Reconceptualising Work with 'Carers': New Directions for Policy and Practice, London: Jessica Kingsley. 